\title{
Dilema ético de la eutanasia
}

\section{Ethical dilemma of euthanasia}

\author{
Lic. Mabel Creagh Peña \\ Policlínico Docente "Dr. Diego Tamayo". La Habana, Cuba.
}

\section{RESUMEN}

La eutanasia significa una muerte buena. Desde el punto de vista jurídico, es la muerte sin sufrimiento físico provocada por propia voluntad de un enfermo incurable. En la práctica consiste en administrar drogas, fármacos u otras sustancias que alivien el dolor aunque con ello se acorte la vida. La decisión de la aplicación de la eutanasia ha sido un problema persistente en la historia de la humanidad, ideologías diversas se enfrentan defendiendo sus argumentos de si debe o no practicarse. El objetivo de este trabajo, es exponer las consideraciones éticas, científicas y religiosas, sobre la práctica de la eutanasia a partir de un análisis histórico desde los tiempos de Platón hasta la actualidad. Lo verdaderamente importante es que el hombre, como ser racional, capaz de revolucionar constantemente la ciencia y la técnica y de transformar la naturaleza en beneficio de la especie, debe también morir con dignidad.

Palabras clave: Eutanasia, ética, bioética, Filosofía y Salud.

\begin{abstract}
Euthanasia means nice death. From the legal viewpoint, it means physical suffering-free provoked death willingly accepted by a terminally-ill patient. In practice, it means to administer drugs, pharmaceuticals or other substances that release pain even though they may reduce lifetime. The decision for euthanasia has been a persistent controversy in the history of mankind; thus various ideologies clash in support of arguments in favour or against this practice. The objective of this paper is to present ethical, scientific and religious considerations on the implementation of euthanasia, taking as a basis a historical analysis covering from
\end{abstract}


Platon up to the present times. It is really important that man, as a rational being capable of permanently revolutionizing science and technique and transforming nature for the benefit of the species, should also die with dignity.

Key words: Euthanasia, ethics, bioethics.

\section{NTRODUCCI ÓN}

En la Antigua Grecia la eutanasia no se planteaba como un problema moral ya que la concepción de la vida era diferente, para este pueblo una mala vida no era digna de ser vivida y por tanto ni el eugenismo, ni la eutanasia complicaban a las personas. Cicerón le da significado a la palabra como muerte digna, honesta y gloriosa. Hipócrates representa una notable excepción: él prohíbe a los médicos la eutanasia activa y la ayuda para cometer suicidio. Platón dice: se dejará morir a quienes no sean sanos de cuerpo ${ }^{1}$. En la Edad Media, bajo la óptica de creencias religiosas cristianas, la práctica de la eutanasia es considerada como pecado, puesto que la persona no puede disponer libremente sobre la vida, que le fue dada por un ser sobrenatural. Las religiones monoteístas como la católica, entienden que el privilegio de la vida, implica conocer la muerte, por lo que se debe estar plenamente consciente del momento final para despedirse de familiares y amigos y poder presentarse en el más allá con un claro conocimiento del fin de la vida.

Con la Modernidad, se desgaja el pensamiento medieval, la perspectiva cristiana deja de ser la única y se conocen y discuten las ideas de la Antigüedad Clásica, se defiende que la salud puede ser alcanzada con el apoyo de la técnica, de las ciencias naturales y de la medicina. Francis Bacon en 1623, defiende que la muerte de un enfermo ayudado por el médico no constituye un problema religioso ya que es al científico a quien le corresponde determinar cuándo un hombre enfermo debe morir o no. Tomás Moro 1516, presenta una sociedad en la que los habitantes justifican el suicidio y también la eutanasia activa, sin usar este nombre. A fines del siglo XIX, en América del Sur existía la persona del despenador o despenadora, encargada de hacer morir a los enfermos desahuciados a petición de los parientes. En el presente, se sustentan diferentes opiniones sobre la eutanasia y son variadas las prácticas médicas y las legalidades en distintos países del mundo. ${ }^{1}$

El propósito de este estudio es exponer algunas concepciones éticas, científicas y religiosas sobre la práctica de la eutanasia.

\section{Dilema ético de la eutanasia}

La eutanasia ha sido manejada por dos corrientes filosóficas, integradas por hombres de ciencia y religión basándose en las creencias y conocimientos que hasta ese momento sus semejantes, como seres sociales, han desarrollado invocando la dignidad humana, tanto para defenderla como para rechazarla. Para sus defensores, la dignidad humana del enfermo consiste en el derecho a elegir libremente el momento de la muerte. Para sus detractores, la dignidad humana es oponerse a este derecho por considerarlo una arbitrariedad humana frente a un 
asunto exclusivamente divino para algunos y exclusivamente científico-legal para otros. $^{2}$

A pesar de que se considera como una decisión final, la eutanasia solo está permitida legalmente en tres países, en el estado de Oregón, Estados Unidos, donde sus ciudadanos aprobaron por referéndum en 1997 la ley de muerte con dignidad; en Holanda, vigente desde abril de 2001, con una serie de garantías y limitantes legales que de no cumplirse pueden desembocar en procesos legales en contra de los médicos, y finalmente en Bélgica, que en septiembre del 2003, se convierte en el segundo país en aprobar leyes a favor de la eutanasia, más flexibles que en el caso de Holanda pero también rígidas en cuanto a procedimientos legales. ${ }^{2}$ El debate sobre licitud moral de la eutanasia ha llegado a exacerbarse tanto que incluso se han creado asociaciones que claman por el reconocimiento de un legítimo derecho a morir con dignidad. El movimiento para la legalización de estas prácticas comenzó en Inglaterra en 1935, con la creación de la Asociación por la Legislación de la Eutanasia, años después se funda otra asociación con el mismo objetivo en Estados Unidos.

En España ha cobrado pujanza la asociación pro derecho a morir dignamente, presidida por el filósofo Salvador Panikér. ${ }^{1}$ En la declaración de Lisboa "Derechos del paciente", enunciada durante la 34 Asamblea Médica Mundial, Portugal 1981, se recoge el derecho del paciente a, después de ser adecuadamente informado sobre el tratamiento, aceptarlo o rechazarlo y morir con dignidad. ${ }^{2}$ En la 35a Asamblea Médica Mundial, ${ }^{3}$ en Venecia, I talia, Octubre 1983, se adopta un "Postulado sobre la Muerte" donde se reafirma que la determinación del momento de la muerte debe ser responsabilidad del médico. Por el contrario en octubre de $1987,{ }^{3}$ en Madrid, en la 38a asamblea Médica Mundial se firma una declaración sobre este particular donde dispone que "La eutanasia, aunque sea por voluntad propia o a petición de sus familiares, es contraria a la ética".

En Ginebra, en $1990,{ }^{3}$ la OMS considera que con el desarrollo de métodos modernos de tratamiento paliativo, no es necesaria la legalización de la eutanasia. En mayo del $2005,^{3}$ en la 170 a Sesión del Consejo Divonne-les-Bains, Francia, se ratifica la Declaración Adoptada en España en octubre 1987. Cuba, en el Simposio Internacional de "Coma y Muerte" realizado en Varadero, Matanzas en el año 2008, sobre la tesis de la muerte, confirma su posición en contra de la eutanasia y defiende los principios médicos de curar, aliviar o acompañar al paciente (Mtra. Elma del Carmen Trejo García. Investigadora Parlamentaria. Legislación Internacional y Estudio de Derecho Comparado de la Eutanasia. Enero, 2007).

Un ejemplo de este debate en la práctica médica se manifiesta al diagnosticar una muerte cerebral. Unas personas consideran acertado el hecho de auxiliar a morir a un paciente a quien se le haya diagnosticado muerte cerebral, lo cual evitará sufrimiento a los familiares, al personal médico y paramédico, evitará gastos de recursos materiales y humanos, dando la posibilidad de brindar atención especializada a pacientes cuya expectativa de vida puede ser mejor. Los que se oponen, mantienen el criterio de que aunque el paciente no puede realizar ninguna de sus funciones por sí mismo, sus órganos vitales no dejarán de funcionar mientras reciba ayuda médica y paramédica especializada, no obstante, oponentes y proponentes, apoyados en el consentimiento científico, reconocen que esta práctica da la posibilidad de disponer de los órganos y tejidos para el trasplante con tiempo suficiente para mantener su perfusión, extracción y conservación una vez certificada la muerte cerebral y con el consentimiento familiar realizar ablaciones de estos órganos. ${ }^{4}$ 
En el Código Civil vigente en la República de Cuba la persona jurídica "es todo ser capaz de derechos y obligaciones", y la personalidad es "el atributo consustancial al ser humano que consiste en sujeto activo o pasivo de relaciones jurídicas", así lo señala Clemente $T$, en la Parte General del Derecho Civil, editado por la Universidad de La Habana, en 1985, citado por Machado Curbelo C. ${ }^{5}$ De acuerdo con esas definiciones, una vez que se ha establecido el diagnóstico de muerte encefálica, el propio estado de irreversibilidad de las funciones del encéfalo en ese paciente, lo excluye de la condición de ser humano, puesto que, al dejar de constituir una unidad socio-psico-biológica ha cesado de ser persona, y por tanto no posee personalidad jurídica. ${ }^{6}$

Este conflicto está determinado por la ética que implique el asunto en cuestión y que para determinar la ética de un proceder hay que hablar de moral, justicia, verdad, conocimiento científico y sociedad, ya que es precisamente en la sociedad donde se forman estos valores que, unidos al conocimiento científico, contribuyen a la formación de la ética médica.

El caso más reciente donde están mezclados renglones tan delicados como ley, religión, moral, cultura, labor del médico, motivos económicos y motivos familiares, fue el de Eluana Englaro, ${ }^{5}$ una joven que permaneció en coma desde 1992 hasta marzo del 2009, cuyo padre luchó en los tribunales y ante la opinión pública por el derecho a la muerte de su hija "a la luz del sol, sin engaños", "Yo no tengo soluciones para proponer, pero creo que este tipo de problemas se deben resolver a través de leyes", anunció el Ministro cuando le preguntaron por este caso. Beppino Englaro, padre de Eluana, hizo una campaña dirigida a las autoridades italianas, incluyendo al Jefe de Estado Carlo Azeglio Ciampi, para que debatiera sobre la moralidad de mantener con vida a "individuos que han perdido de forma irreversible la posibilidad de experimentar cualquier tipo de emociones". "Estas personas se encuentran imposibilitadas para decidir si quieren ser mantenidas en estado vegetativo por años o décadas", dijo Englaro. El médico que ayudó al padre de Eluana a llevar el caso a los tribunales, el neurólogo Carlo Alberto Defanti, explicó que "hace treinta años, situaciones como esta no se producían, porque son producto de la terapia intensiva, los pacientes son cuerpo sin pensamientos, sin comunicación, sin posibilidad de cambiar. Se podría decir que son cuerpos sin alma, sin espíritu."

La ética médica es y será siempre la evaluación política de un sistema de salud, porque las políticas de salud afectan directa o indirectamente todos los aspectos de la vida cotidiana: las acciones, los comportamientos y las decisiones. Pueden además, prohibir conductas que se perciben como riesgosas, alentar las que se consideran beneficiosas, proteger los derechos y el bienestar de algunas poblaciones, impulsar ciertas actividades o proporcionar beneficios directos a los ciudadanos necesitados. Las políticas reguladoras pueden definir acreditaciones profesionales, establecer controles de precios para los bienes y servicios, determinar criterios de calidad, seguridad y eficacia para los servicios de la salud y tratar cuestiones de regulación social, tales como las relacionadas con la seguridad social y ocupacional.

Los profesionales cubanos de la salud han podido constatar que en la mayoría de los países de este mundo unipolar, médicos, paramédicos, trabajadores de la salud en general y familiares de estos pacientes, ante un diagnóstico de muerte cerebral deciden desconectarlos de las máquinas que mantienen sus órganos vitales funcionando, para evitar una estadía hospitalaria prolongada que redunde en gastos excesivos para los familiares al tener que pagar por el derecho a una cama, a la atención especializada, por la utilización de recursos humanos y materiales, la compra de medicamentos que esta enfermedad requiere para mantener una evolución satisfactoria o estable y los recursos científico-técnicos que permitan a los 
especialistas llegar a un diagnóstico mejor y certero, ven con desconcierto como esta decisión la toman de la forma mas rápida posible y está dado porque mientras más se demoren en decidir, más tendrán que pagar y es que en estos países con la muerte del paciente no termina el sufrimiento de los familiares pues estos instantáneamente se vuelven deudores de los servicios médicos que ha recibido el paciente, aun en algunas instituciones estatales, lo que genera grandes sacrificios para pagar la deuda adquirida, por tanto, ellos pueden hacer o hacen algunas de las maniobras siguientes:

- Retirar a sus hijos de las escuelas que tienen que pagar.

- Trabajar en más de 2 o 3 centros laborales.

- Hacer turnos de trabajo dobles.

- Vender sus propiedades (casas, autos, negocios y otros).

En muchos de estos países se ha constatado cómo las clínicas privadas se dedican a mercantilizar la salud y le brindan al hombre todos los servicios que necesite, allí se encuentran todos los recursos humanos, materiales y técnicos que se requiera para mantener la vida de estos pacientes el tiempo que sea necesario y todo ello redundará en beneficios monetarios para los dueños.

El sistema de salud cubano basado en los principios del carácter estatal socialista, gratuito, accesible, preventivo y altamente calificado, unido a la ciencia, la docencia y la práctica médica con participación de las masas en las tareas de salud, hacen que cobren una dimensión excepcional los aspectos mencionados e introduce otros como el del internacionalismo, la solidaridad humana y el patriotismo, pero sobre todas las cosas, cuando los cubanos se enfrentan a situaciones difíciles con los pacientes, tienen el privilegio de pensar solamente en el hombre enfermo, en las oportunidades que la revolución científico técnica de nuestro tiempo pueda redundar en beneficio para su salud y la calidad de vida, sin tener que pensar en dinero ni pérdidas monetarias o materiales futuras. ${ }^{7,8}$

El amor al trabajo y al hombre, el respeto por la vida y al ser humano en su integridad, el sentido del deber, la responsabilidad, la honestidad, el altruismo, el desinterés y la dignidad profesional entre otros, son valores que deben llegar a convertirse en virtudes que caractericen la actuación del médico al asimilarse como valores personalizados, expresión legitima y auténtica del sujeto que los asume. ${ }^{9,10}$

Contando entonces con una sociedad culta, responsable y honesta, con profesionales dispuestos y preparados para afrontar las más duras decisiones acerca de la vida humana, con un sistema de salud que garantice la verdadera medicina, la que precave, cabe cuestionarse nuevamente la ilegalidad de elegir entre una muerte necesaria desde el punto de vista humano, que evite el dolor y el sufrimiento personal y familiar y que por demás asegure, quizás, la vida larga y efectiva de otros semejantes o el corto espacio de vida llena de dolor y sufrimiento que media entre la enfermedad incurable y la muerte irremediable, sin contar los gastos que se ocasionan por considerarlos derecho soberano del paciente.

Determinar si un hombre debe morir o no, por los siglos de los siglos encontrará oponentes y proponentes y de esta investigación se deriva que el hombre debe mirar a su alrededor, escuchar y preguntar el por qué de una decisión como esta, buscar la mejor manera de aliviar al ser humano de sufrimientos y preocupaciones, ubicarse en su sistema, cultura y religión, entender que el lenguaje de la ética ha sido adoptado no solo por pacientes, familias, médicos, economistas, ministros, 
jueces y administrativos de la salud, independientemente de su corriente filosófica y su sistema social y entender que lo único verdaderamente importante es que el hombre, como ser racional, capaz de revolucionar constantemente la ciencia y la técnica y de transformar la naturaleza en beneficio de la especie, debe también, morir con dignidad.

\section{REFERENCI AS BI BLI OGRÁFI CAS}

1. Colectivo de Autores. Lectura de Filosofía, Salud y Sociedad. La Habana: Editorial Ciencias Médicas: 2004

2. Acosta Sariego JR. ¿Quien debe decidir? Rev Avances Médicos Cuba. 1996; Año III No 7. p. 60.

3. Amaro Cano M del C. Problemas Éticos y Bioéticos en enfermería. La Habana: Editorial Ciencias Médicas; 2005.

4. Sánchez Caro J. Aspectos jurídicos de interés en relación con los transplantes de órganos. Nefrología. 1994; 14(supl 1):64-9.

5. Machado Curbelo C. Criterios cubanos para el diagnóstico de la muerte encefálica. La Habana: Editorial Ciencias Médicas; 1992.

6. Vázquez R. Teorías y principios normativos en bioética. México, D.F.: Instituto Normativo Autónomo de México; 2000.

7. Apropiación Social de la Ciencia. Revista Ciencia, Tecnología y Sociedad. Enero, 2008, No. 10.

8. Gracia D. ¿Que es un sistema justo de servicios de salud? Principios para la asignación de recursos escasos. Publicación científica No. 527. Washington, D.C: OPS; 1990.

9. Barreto Vaquero D. Reflexiones en torno a la eutanasia como problema de salud pública. Rev Cubana Salud Pública [Internet]. 2004 Mar [citado 2011 Nov 25];30(1): Disponible en: http://scielo.sld.cu/scielo.php?script=sci_arttext\&pid=S086434662004000100010\&lng=es

10. Diagnostico Neurofisiológico de muerte cerebral en la donación de órganos. Madrid: SANED; 1986.

Recibido: 27 de junio de 2011.

Aprobado: 18 de octubre de 2011.

Mabel Creagh Peña. Puerta Cerrada 11 e/ Suárez y Factoría. Habana Vieja. La Habana, Cuba.

Teléf.: 8610005, 2082129. Correo electrónico: mabel.creagh@infomed.sld.cu 